\section{Os Princípios do Estado Socioambiental de Direito e sua Leitura Jurisprudencial}

\section{The Principles of the Socioenvironmental State of LAW ANd Their JuRISPRUdentiaL READING}

\author{
Haide Maria Hupffer * \\ William Gabriel Waclawovsky ** \\ Roberta Cassel Greenfield ***
}

Resumo: Este estudo utiliza o método hermenêutico para realizar a leitura doutrinária e jurisprudencial da juridicização dos princípios ambientais, o que se deu a partir da redação do caput do art. 225 da Constituição Federal, enfrentando a denomina solidariedade intergeracional, o princípio da prevenção, precaução, poluidor-pagador, usuário-pagador, cooperação internacional e a participação comunitária. A abordagem do princípio da função social da propriedade fecha o estudo, apresentando um caso em que se entendeu constitucional a progressividade das alíquotas do IPTU em razão da localização e destinação dada ao imóvel, o que viria em cumprimento à função social da propriedade.

Palavras-chave: Princípios Ambientais, Estado Socioambiental de Direito, Jurisprudência Ambiental.

Abstract: This study uses the hermeneutic method to carry out the doctrinal and jurisprudential reading of the juridical process for environmental principles, resulting from the writing of the article 225's caput in the Federal Constitution, facing what is called of intergenerational solidarity, prevention principle, precaution, polluter-payer, user-payer, international cooperation and community participation. The approach of the property social function principle closes the study, presenting a case in which it was understood the progressivity of the iptu's rate is constitutional because of the location and the destination given to the landed property, what would fulfill the social function of the property.

Keywords: Environmental Principles, Socioenvironmental State of Law, Environmental Jurisprudence. 


\section{INTRODUÇÃO}

No Direito Ambiental, os princípios assumem papel de destaque, mormente a importância do bem jurídico tutelado, que requer uma tutela efetiva e atuante, o que, se fosse realizado apenas com supedâneo em regras jurídicas, limitaria muito o campo de atuação e as hipóteses de aplicação das regras de responsabilização. Tanto é assim, que um dos princípios reitores do Direito Ambiental - o princípio do poluidor-pagador ou princípio da responsabilização foi um dos primeiros a surgir na ordem jurídica ambiental e mesmo após a edição de inúmeras leis - veiculadoras que são das regras jurídicas - continua sendo uma constante de fundamentação nas jurisprudências em matéria ambiental.

O Direito Ambiental de vertente alemã se fundamenta em três grandes princípios, dos quais a doutrina pátria veio a decorrer outros, não de somenos importância e que serão a seguir abordados. São eles: o princípio da prevenção (vorsogeprinzip), o princípio do poluidor-pagador ou princípio da responsabilização (veuersacherprinzip) e o princípio da cooperação ou da participação (koopetationsprinzip).

Assim, no presente estudo, serão examinados os princípios do Estado Socioambiental de Direito e a consequente internalização da tutela do bem jurídico ambiental por parte do sistema do Direito. A análise proposta perpassa a juridicização do valor ético representado pela alteridade, o que se deu a partir da redação do caput do art. 225 da Constituição Federal, que instituiu o que a doutrina veio a denominar de solidariedade intergeracional. Ao depois, analisase a impossibilidade de se retroceder o mínimo existencial ecológico, dever que redunda no princípio da proibição de retrocesso, umbilicalmente ligado à concepção do direito das futuras gerações a um meio ambiente ecologicamente equilibrado e sadio como um direito fundamental, impassível de redução das suas garantias, portanto. Em sintonia com a tutela ambiental, o princípio do desenvolvimento sustentável é abordado como um dever de modulação e integração de dois valores jurídicos de importância primordial na ordem jurídica brasileira, qual seja o desenvolvimento econômico e a proteção do meio ambiente.

Seguindo essa intelecção, aborda-se a atuação do Direito quando diante de potencialidade de causação de dano ambiental, perpassando a abordagem do princípio da prevenção lato sensu, que abarca a prevenção stricto sensu e a precaução. Ainda, aborda-se o princípio do poluidor-pagador como uma forma de internalização dos custos de transação (que deverão ser suportados pelo 
empreendedor-poluidor), desonerando a sociedade de um ônus que não é seu. Seguindo essa lógica, enfrenta-se o princípio do usuário-pagador, que tem por mote evitar a escassez dos bens ambientais tutelados, por meio da aplicação, por exemplo, de taxas sobre serviços ou bens que contribuam com a escassez de algum recurso natural, evitando, dessa forma, o seu consumo ou utilização indiscriminados. Em razão da globalidade, transtemporalidade e invisibilidade dos danos ambientais representados pela nova formatação assumida pela sociedade de risco, aborda-se, ato contínuo, dois importantes princípios da tutela comunitária do meio ambiente, quais sejam a cooperação internacional e a participação comunitária. Por fim, apresenta-se o princípio da função social da propriedade para fechar o estudo.

\section{PRINCÍPIO DA EQUIDADE OU DA SOLIDARIEDADE INTERGERACIONAL}

A Constituição Federal de 1988, em seu art. 225, caput, consagrou o que a doutrina veio a denominar de equidade intergeracional ou solidariedade intergeracional, isto é, o dever que a presente geração possui em relação à preservação dos recursos ambientais, impondo-se que transfira para as futuras gerações o bem ambiental em condições não inferiores às recebidas, mantendose, assim, a equidade no acesso aos recursos e aos benefícios proporcionados pelo ambiente, como a qualidade do ar, das águas, a biodiversidade, entre tantas outras características que não devem ser passadas às futuras gerações em condições inferiores às recebidas.

Com efeito, o princípio da solidariedade intergeracional veio a edificar a ideia de que não há prioridade da geração presente em relação às futuras, que possuem igual direito a um meio ambiente equilibrado e sadio. Trata-se, em última análise, da juridicização do valor ético da alteridade, isto é, da imposição pela ordem jurídica do dever de respeitar um bem cujo titular não é somente a geração presente, mas também as futuras.

Canotilho (2010) situa em três campos os interesses das futuras gerações que são carecedores de tutela: [a] o campo das alterações irreversíveis dos ecossistemas terrestres em consequência dos efeitos cumulativos da atividade humana sobre o ambiente; [b] o campo do esgotamento dos recursos, derivado de um aproveitamento não racional e da indiferença relativamente à capacidade de renovação e da estabilidade ecológica e, por fim, [c] o campo dos riscos duradouros. 
Assim, é imprescindível que o possível seja caracterizado nas sociedades do risco global como resultado de processos que buscam os melhores pontos de consensos democraticamente estruturados em torno do enfrentamento da crise ecológica. Nesse sentido, conclui, com a percuciência que lhe é própria, o citado autor, que a possibilidade de um futuro não é promessa, mas compromisso, a ser realizado mediante a observância de uma tríade de condições, estruturada na participação, na informação e na repartição de responsabilidades (solidariedade) (AYALA, 2010). Daí porque De Giorgi (1998) afirma que o risco é a forma construtiva de estabelecermos vínculos obrigacionais com o futuro.

Destarte, esse princípio também pode ser visto como princípio da solidariedade intergeracional, na medida em que impõe um dever de proteção solidário entre as gerações. Brown Weiss (1992) salienta que o substrato jurídico desse princípio é formado por três subprincípios: A conservação de opções (que impõe que a diversidade dos recursos ambientais não seja reduzida), a conservação da qualidade e a conservação de acesso.

\subsection{SUBPRINCÍPIO DA PROIBIÇÃO DE RETROCESSO}

O fundamento mais importante por trás da formulação do princípio da equidade intergeracional reside, sem sombra de dúvida, no princípio da proibição de retrocesso. Esse princípio visa a tutelar o "mínimo existencial ecológico". Molinaro (2007, p. 103) afirma que o princípio da retrogradação socioambiental é estruturante de um Estado Socioambiental e Democrático de Direito, de modo que o referido autor o concebe como um "lugar de encontro", onde os cidadãos possam conviver e se desenvolver com segurança, liberdade e igualdade substancial, pressupondo, pois, uma ambiência saudável, sustentadora e sustentada tanto para as presentes gerações como para as gerações futuras. Com efeito, como leciona Canotilho (1998, p. 320-321),

o núcleo essencial dos direitos sociais já realizado e efectivado através de medidas legislativas [...] deve considerar-se constitucionalmente garantido, sendo inconstitucionais quaisquer medidas estaduais que, sem a criação de outros esquemas alternativos ou compensatórios, se traduzam na prática numa "anulação", "revogação" ou "aniquilação" pura e simples desse núcleo essencial. A liberdade de conformação do legislador e inerente auto-reversibilidade têm como limite o núcleo essencial já realizado.

Na mesma linha, Ayala (2010, p.361) admite como um dos efeitos da proibição de retrocesso ambiental a impossibilidade do Estado poder autorizar, 
tolerar ou atribuir proteção legal a ações ou omissões que possam gerar degradação da qualidade dos recursos naturais. Dito de outro modo, o Estado tem o dever de assegurar que essa "qualidade não seja degrada, por deficiência em sua proteção normativa, deficiência de proteção ou por insuficiência de proteção". O autor faz um alerta de que não é só o Estado que está vinculado a este subprincípio. Para Ayala (2010), a ordem constitucional brasileira em seu art. 225 conclama que a comunidade tem o dever de atuar na defesa do meio ambiente e proteger os interesses das futuras gerações. Assim, não exceder os limites constitucionais do exercício das liberdades econômicas do particular, representa para o autor um dos efeitos da proibição do retrocesso ecológico.

Sob esta perspectiva e no contexto de cidades sustentáveis, bem justificou o ministro Herman Benjamin (BRASIL, 2010), em decisão sobre a edificação irregular de um prédio de nove andares em local em que era permitida apenas a construção de residências unifamiliares, ao arguentar que:

[...] o exercício do ius variandi, para flexibilizar restrições urbanísticoambientais contratuais, haverá de respeitar o ato jurídico perfeito e o licenciamento do empreendimento, pressuposto geral, que no Direito Urbanístico, bem como no Direito Ambiental, é decorrência da crescente escassez de espaços verdes e dilapidação da qualidade de vida nas cidades. Por isso mesmo, submete-se ao princípio da não-regressão (ou, por outra terminologia, princípio da proibição de retrocesso), garantia de que os avanços urbanístico-ambientais conquistados no passado não serão diluídos, destruídos ou negados pela geração atual ou pelas seguintes.

Com efeito, a proibição de retrocesso está relacionada ao princípio da segurança jurídica fundamentada no princípio do Estado Democrático de Direito guardando, ainda, conexão com a garantia da proteção dos direitos fundamentais, dentre os quais a dignidade da pessoa humana e do mínimo existencial socioambiental (SARLET; FENSTERSEIFER, 2011). Assim, lançadas tais premissas, a versão do novo Código Florestal aprovada em 24 de maio de 2011 pela Câmara dos Deputados, contraria o princípio da proibição de retrocesso, ou seja, viola o $\S 1^{\circ}$ do art. 225 da Constituição Federal e, se aprovado na íntegra, é um obstáculo à concretização dos direitos fundamentais e socioambientais. A redução da proteção de áreas de preservação permanente, a dispensa da recuperação de danos ambientais e anistia ampla para aqueles que continuaram desmatando ilegalmente são alguns exemplos de afronta à Constituição Federal e leis infraconstitucionais. 
Em outro contexto, Aragão (2010, p.58) estuda, no Direito Comunitário, como no caso da integração regional da Europa. Em casos assim, quando há integração entre países, vigora o que se denomina de proibição do mínimo denominador comum, segundo o qual o novo regime jurídico decorrente da integração entre os países deverá assegurar um nível de proteção ambiental no mínimo igual ou - o que geralmente se verifica na prática do Direito Comunitário - superior à média dos regimes individuais.

Dessa forma, o referido princípio atua no sentido de impor que as condições de proteção do meio ambiente alcançadas na ordem jurídica vigente não podem ser reduzidas injustificadamente, apenas aperfeiçoadas, elevando o nível de proteção do bem ambiental.

\section{PRINCÍPIO DO DESENVOLVIMENTO SUSTENTÁVEL}

O princípio do desenvolvimento sustentável parte de dois pressupostos: [a] os recursos naturais são finitos e exauríveis; [b] a sociedade humana não se limita à presente geração.

A proteção do meio ambiente deve ser considerada parte integrante do processo de desenvolvimento, ou seja, esse princípio destaca a necessidade de se considerar a variável ambiental na tomada das decisões (MARCHESAN; STEIGLEDER; CAPPELLI, 2008). Assim, sua finalidade precípua é garantir o atendimento das necessidades do presente sem comprometer a possibilidade de as gerações futuras satisfazerem, também, as suas necessidades. Busca este princípio, assim, conciliar o desenvolvimento econômico, do qual decorre invariável potencialidade de degradação ambiental, com a proteção e preservação do meio ambiente. Álvarez (2000), com muita percuciência, leciona que a objetividade jurídica deste princípio reside na modulação e integração de dois valores jurídicos de suma importância (o desenvolvimento econômico e a proteção do meio ambiente).

A Constituição brasileira, por meio do art. 186, inciso II, aproximou o princípio do desenvolvimento sustentável da função social da propriedade, ao afirmar que uma propriedade cumprirá a função social que dela se exige na medida em que utilizar adequadamente os recursos naturais disponíveis e preservar o meio ambiente. Assim, verifica-se que, no mesmo passo em que a propriedade não pode ser improdutiva (sob pena de não cumprir sua função social), também não pode, por outro viés, representar degradação do meio ambiente. Desse modo, no texto constitucional, o conceito de propriedade 
cumpridora da sua função social pressupõe o atendimento do princípio do desenvolvimento sustentável.

Uma aplicação prática do princípio em comento pode ser observada no julgamento do REsp n ${ }^{\circ}$ 1.094.873/SP, que se originou de uma ação civil pública proposta pelo Ministério Público do Estado de São Paulo em razão de práticas de queima da palha como método preparatório para a colheita da cana-deaçúcar no interior paulista. O parquet pediu a proibição da queimada e condenação dos infratores a indenizar os danos ambientais provocados. O pedido foi deferido em primeiro e segundo graus. Interposto Recurso Especial para o STJ sob a alegação de que o art. 27 do Código Florestal Brasileiro (Lei ${ }^{\circ}$ 4.771/65) autorizava o uso de fogo se peculiaridades locais ou regionais justificarem tal prática em atividades agropastoris e florestais, mediante a permissão do poder público, o relator, ministro Humberto Martins, afastando uma interpretação meramente dogmática do Código Florestal, e recorrendo a uma interpretação interdisciplinar, destacou a necessidade de o desenvolvimento ser sustentável e anotou que, existindo formas menos lesivas de exploração, o interesse econômico não pode prevalecer sobre a proteção ambiental. Com efeito, demonstrou o relator que a queima da palha da cana-de-açúcar libera gases nocivos à saúde humana e às demais espécies animais, existindo, por outro lado, tecnologias atuais capazes de substituir a queimada sem inviabilizar a atividade econômica da indústria (BRASIL, 2009).

\section{PRINCÍPIO DA PREVENÇÃO}

Trata-se do princípio basilar no sistema do Direito Ambiental. O princípio da prevenção lato sensu é composto pela precaução e pela prevenção stricto sensu. Em ambos se procura evitar a ocorrência de lesão ao ambiente. $\mathrm{Na}$ precaução, lida-se com a probabilidade de dano ao ambiente, com um risco de ocorrência desconhecida ou de proporções desconhecidas. Sua função é "in dúbio pro ambiente" (ARAGÃO, 2010, p.62). É que, o risco ecológico, antes calculável e previsível, apresenta novas características e anuncia a probabilidade de ocorrência de grandes desastres, que poderão comprometer o meio ambiente e a saúde dos seres vivos. Assim, diante desse cenário, vislumbra-se a perda das certezas por parte da ciência (PRIGOGINE, 1996), que, por vezes, mostrase insuficiente para dar resposta a problemas que, não raro, foram gerados e impulsionados pelas suas próprias descobertas (FERREIRA, 2004).

A ciência, ao se deparar com a dúvida, passa a ter de aplicar a "si própria as faculdades da crítica que até então eram voltadas para a natureza”, 
culminando com a áspera constatação de que a ciência "perdeu o monopólio do veredicto"; o princípio da precaução agora apresenta o ceticismo à ciência (OST, 2005, p.326). Giraud (1997), por sua vez, constata a existência de um paradoxo entre a certeza de irreversibilidade e a incerteza de irreversibilidade do dano.

Dessa forma, o princípio da precaução erige-se no Estado Socioambiental de Direito a partir de três irritações provenientes da incerteza científica, quais sejam: [a] a incerteza científica acerca da existência e da natureza do dano ambiental; [b] a incerteza científica em relação à extensão dos danos; e [c] a incerteza em relação ao nexo de causalidade existente entre determinada conduta e determinado dano.

Destarte, a importância dogmática do princípio da precaução reside no fato de a sociedade de risco (BECK, 1992) ser governada por mecanismos que geram a denominada irresponsabilidade organizada, na qual o aspecto econômico da produção massificada e em larga escala é supervalorizado em detrimento da proteção do meio ambiente. Além disso, essa nova forma de sociedade não distribui mais apenas o lucro, exprimido na capacidade de produção de riquezas, mas também riscos, em razão das tecnologias empregadas para a produção dessa riqueza.

Trata-se de tecnologias cujos efeitos ainda não foram suficientemente explorados a ponto de se delimitar precisamente quais os efeitos e adversidades que decorrem do seu uso. Dessa forma, o referido princípio atua como mecanismo regulador dessa falha social, funcionando como uma espécie de inibidor do lucro a todo custo, impondo o respeito à responsabilidade ambiental em uma economia de mercado. Por esse prisma, o princípio da precaução, figurando em uma sociedade sujeita a riscos, perigos e ameaças, impõe um dever ao Estado e à coletividade de realizarem o prognóstico das possíveis e prováveis consequências ambientais decorrentes de suas decisões e de fatos jurídicos externos, adotando assim, importantes medidas que os previnam ou minimizem.

O princípio da precaução guarda estreito vínculo como os princípios do desenvolvimento sustentável e equidade intergeracional ao se propor a conciliar "o progresso proporcionado pela indústria, pela ciência e pelas novas tecnologias com os imperativos de proteção do meio ambiente, como direito fundamental das presentes e futuras gerações" (NOGUEIRA, 2004, p.194).

Por outro lado, não se pode desconsiderar que o princípio da precaução deve suplantar a "pressa, a precipitação, a improvisação, a rapidez insensata e a vontade de resultado imediato" (MACAHDO, 2001, p.1082). É dizer, o 
enfoque preventivo deve prevalecer no que respeita aos danos graves e irreversíveis, sobretudo aqueles cujos efeitos se produzem a longo prazo e tem a aptidão de comprometer a saúde e o bem estar das futuras gerações.

A precaução serviu também como forma de consolidar o Direito Ambiental na tutela do ambiente, uma vez que os instrumentos utilizados para essa tutela, até então, eram decorrentes do Direito Civil e do Direito Penal, onde requisitos como a "certeza e a previsibilidade do dano eram cogentes para a imposição de medidas preventivas". Agora, com a institucionalização do princípio da precaução, "separa-se a noção de ato ilícito de dano, permitindo, assim, que a tutela ambiental se antecipe ao dano" (BENJAMIN, 2001, p.71-72).

O princípio da precaução não importa na prostração diante do medo, nem elimina a audácia necessária para a evolução econômica da sociedade, mas equivale à busca de segurança para o meio ambiente, que é requisito indispensável à continuidade da vida no planeta (MACHADO, 1994). Diante disso, constatamos a necessidade de se estabelecer critérios para a aplicação do referido princípio, isto é, as situações nas quais uma determinada conduta deverá ser reprimida - com a caracterização de ato ilícito - a fim de se tutelar o bem ambiental.

Nesse conduto de exposição, a doutrina especializada perfilha os requisitos para a caracterização da ilicitude da conduta de risco a fim de legitimar a imposição de medidas preventivas. Carvalho (2008, p.155-157) propõe que a configuração da ilicitude do risco ambiental deve ser realizada por meio da investigação da "probabilidade de ocorrência do dano e da magnitude do risco". Assim, somente aqueles riscos cuja equação entre a sua "probabilidade de ocorrência futura e a magnitude das suas conseqüências nocivas indicar a sua intolerabilidade social" devem ser considerados ilícitos, justificando a imposição de medidas preventivas.

Nesse sentido, a adoção desse princípio pode ser classificada, segundo Nogueira (2004), p.201-202), em três principais correntes doutrinárias, a saber:

[a] a radical, que visa a garantir o risco zero, defendendo a desativação da atividade potencialmente degradadora e a inversão do ônus da prova, implicando a aplicação desta última, em o empreendedor, quando demandado em juízo, provar que sua atividade não é potencialmente poluidora;

[b] a minimalista, que, para a determinação da abstenção da prática da atividade potencialmente degradadora requer a existência de riscos sérios e irreversíveis e mantém inalterada a sistemática da distribuição do ônus da prova, aplicando-se, por conseguinte, a regra clássica e vigente em nosso ordenamento 
processual, que é aquele disposto no art. 333 do Código de Processo Civil, cabendo o ônus de provar fato constitutivo do direito ao autor da demanda e o ônus de provar os fatos impeditivos, modificativos ou extintivos do direito do autor ao réu da demanda.

[c] por fim, conciliando as duas correntes antagônicas anteriores, a terceira corrente, classificada como intermediária, propõe que o risco apto a impor a abstenção da medida seja crível e admitido como plausível por parte significativa da comunidade científica - daí se concluindo que o risco abstrato ou de pouca probabilidade de ocorrência não enseja a aplicação das medidas preventivas. Em relação ao ônus da prova, defende a aplicação da carga dinâmica da prova.

Analisando os julgados existentes no âmbito do Superior Tribunal de Justiça , pode-se verificar uma clara tendência à adoção da corrente intermediária, com apenas uma ressalva. Como a carga dinâmica da prova ainda não é prevista no ordenamento processual brasileiro, aquela corte tem aplicado a inversão do ônus da prova, cumprindo ao empreendedor demonstrar que inexiste nexo de causalidade entre a sua atividade e o dano ambiental, utilizando como critério para a aplicação da inversão do ônus probandi os mesmos critérios utilizados para a análise da adoção de medidas preventivas, o que implica em verificar se o risco em questão é crível. Sendo crível, determina a inversão do ônus da prova, não sendo crível, mantém a sistemática de distribuição do ônus da prova conforme o art. 333 do Código de Processo Civil.

Tal princípio é muito utilizado como "causa de pedir próxima em diversas ações civis públicas, como é o caso da ação civil pública que objetiva impedir o cultivo da soja transgênica sem a realização do prévio estudo de impacto ambiental", previsto no art. 225, § $1^{\circ}$, IV, da Constituição Federal. É fundamento, também, para as demandas que objetivam retirar ou evitar a construção de estações de rádio-base de telefonia móvel em diversos locais do país, considerando não haver certeza científica acerca dos possíveis efeitos nocivos das radiações eletromagnéticas não-ionizantes geradas por esses equipamentos de telefonia celular (MARCHESAN; STEIGLEDER; CAPPELLI, 2008, p.32).

É importante frisar que se deve ao princípio da precaução o reconhecimento, por parte dos tribunais pátrios, da autonomia do ilícito em relação ao dano, possibilitando que seja declarada ilícita uma conduta que ainda não gerou dano, mas que pode vir a gerá-lo. Descola-se, dessa forma, o dano da atuação do Direito.

Já na prevenção stricto sensu, o resultado lesivo de determinada conduta é conhecido e certo - por isso que, aqui, em vez de risco, fala-se de perigo -, 
cabendo, pois, evitar a causação do dano com a abstenção da conduta. Enquanto a precaução é decorrência da sociedade de risco, a prevenção decorre da sociedade industrial.

Com efeito, na sociedade industrial tem-se a existência de nexo de causalidade determinístico entre conduta e dano, sendo certa a ocorrência do efeito se praticada a causa, cabendo, diante disso, prevenir o efeito (= dano ambiental) por meio da repressão à prática da causa (= conduta humana). Com efeito, a previsão normativa do princípio da prevenção vem disposta no art. 14, $\S 1^{\circ}$, da Lei n ${ }^{\circ} 6.938 / 81$, bem como no art. 225, $\S 3^{\circ}$, da Constituição Federal. Cumpre ser anotado que a imposição da sanção jurídica prevista para a conduta transgressora pressupõe a ocorrência de dano ambiental, ao contrário do que ocorre com o princípio da precaução, onde, justamente em razão da incerteza científica em relação ao dano e as suas conseqüências, a atuação do Direito é anterior ao dano, incidindo sobre a conduta do agente objetivamente considerada.

Ademais, é importante destacar que a adoção de medidas preventivas não pressupõe a intervenção do Poder Judiciário, estando direcionadas também aos órgãos e entidades da Administração Pública (Poder Executivo). O estudo de impacto ambiental - previsto no art. 225, $\S 1^{\circ}$, IV, da Constituição Federal por exemplo, necessário à licença de atividades públicas e privadas potencialmente lesivas ao meio ambiente, é um inegável procedimento administrativo de cunho preventivo.

\section{PRINCÍPIO DO POLUIDOR-PAGADOR}

Esse princípio se assenta na constatação de que as externalidades negativas geradas pelos agentes econômicos devem ser suportadas por estes mesmos, a fim de que não se onere o meio ambiente com os custos de transação gerados pelo mercado. Dessa forma, impõe-se ao empreendedor a assimilação das externalidades negativas, que refletirá no aumento do preço do produto ou serviço ao consumidor final, entretanto - e é aqui que a lógica desse princípio opera - esse custo não ficará a cargo do ambiente.

Há que se fazer a necessária ressalva ao conceito equivocado que se pode extrair do princípio em exame. Não se trata, como poderia se supor em uma primeira análise, de uma espécie de licença para poluir mediante o "pagamento" dessa poluição. O que se pretende é que a imposição de multa a quem polui atue como fator desestimulante de práticas degradantes. Nessa linha de intelecção, podemos concluir que tal princípio é, em verdade, um "princípio de solidariedade social", na medida em que impõe ao agente que evite a 
degradação e, não tendo logrado evitá-la, deverá responder pelo dano causado. Assim, pode-se afirmar que, em um primeiro momento da tutela ambiental, temos o princípio do poluidor-pagador e, em um segundo momento - quando o poluidor-pagador não foi suficiente para evitar o dano - a responsabilização ambiental pelo dano causado. Diante disso, Fiorillo (2010, p. 88) identifica no referido princípio duas órbitas de alcance: [a] em um primeiro momento possui um caráter preventivo e $[\mathrm{b}]$ em um segundo momento, concretizado o dano, um caráter repressivo.

Registra-se que o objetivo maior desse princípio é fazer com que o poluidor passe a integrar, de maneira permanente, no seu processo de produção e fabricação, o valor econômico que consubstancia o conjunto dos custos ambientais (MARCHESAN; STEIGLEDER; CAPPELLI, 2008). Ainda, como observa Fiorillo (2010), o princípio em questão determina a incidência a aplicação de alguns aspectos do regime jurídico da responsabilidade civil aos danos ambientais: [a] a responsabilidade civil objetiva; [b] a prioridade da reparação específica do dano ambiental; e [c] solidariedade para suportar os danos causados ao meio ambiente.

Nesse sentido, cumpre ser estabelecido que, em alguns casos específicos, a legislação ambiental permite a degradação da qualidade ambiental - como ocorre nos empreendimentos sujeitos ao licenciamento ambiental - mas esta jamais permitirá a poluição, que consistirá sempre em um ilícito ambiental (seja do ponto de vista da responsabilidade civil, como da penal).

Por fim, leciona Aragão que os fins colimados por esse princípio dizem com a implementação da precaução, da prevenção e da redistribuição dos custos das medidas públicas. Assim, afirma a citada doutrinadora que se aos empreendedores não forem dadas outras alternativas a não ser deixar de poluir ou ter que suportar um custo econômico em favor do Estado, então os empreendedores terão de escolher a opção economicamente mais vantajosa: [a] adotar as medidas de prevenção ou precaução necessárias a evitar a poluição ou [b] manter o empreendimento em um nível de produção que ainda se demonstre economicamente rentável após suportar os custos decorrentes da poluição (ARAGÃO, 2010).

\section{PRINCÍPIO DO USUÁRIO-PAGADOR}

Previsto no art. $4^{\circ}$, VII, in fine, da Lei da Política Nacional do Meio Ambiente (Lei n ${ }^{\circ} 6.938 / 81$ ), trata-se de cobrar do usuário pela utilização com finalidade econômica de um recurso ambiental. 
A Constituição Federal faz referência expressa ao poluidor-pagador nos $\S \S 2^{\circ}$ e $3^{\circ}$ do art. 225 . Com efeito, ao passo em que o princípio do poluidorpagador busca evitar a degradação dos bens tutelados, o princípio do usuáriopagador visa a evitar a escassez dos bens tutelados. Correta, pois, a leitura econômica que assume o princípio do usuário-pagador. A vulnerabilidade dos recursos naturais exige respostas diferenciadas do Direito e da Economia na tutela ambiental que vincula as necessidades do presente ao interesse das futuras gerações.

Nesse pêndulo de construção de idéias, sob o prisma do Direito Econômico, o princípio do usuário-pagador representa a assimilação - e consequente e internalização pelo Direito Ambiental - das chamadas externalidades negativas (falhas de mercado). Transfere-se (internaliza-se), assim, os custos sociais de determinada atividade, para o empreendedor, desonerando a sociedade de um ônus que não é seu. Tais falhas de mercado, por importarem em degradação da qualidade ambiental, recebem uma resposta do sistema do Direito que manda (haja vista que a natureza do Direito é coercitiva) que o poluidor evite a degradação ou indenize a degradação causada, bem assim o usuário evite o uso tendente à escassez ou, caso assim o faça, pague por isso. Com tal perspectiva, pontua Sarcinelli (2008) que os custos que o empreendedor terá para fornecer seu produto ou serviço constituirão nos denominados custos de transação, que serão repassados para o consumidor final (o que importa no aumento do preço de determinado produto cuja produção represente potencial degradação ambiental ou mesmo na cobrança pela utilização de um recurso limitado, como a água).

Vejamos como tais questões se reproduzem: a deterioração ambiental e o excesso de consumo gera custos sociais para as presentes e futuras gerações e, se estes custos ambientais não forem refletidos nas decisões do sistema econômico com a correta sinalização nos preços dos produtos ou serviços, as consequências da escassez e da degradação são jogadas para as gerações futuras. Por isso, a necessidade do Direito repensar o direito de uso e de posse dos bens ambientais, o que significará assumir a necessidade de uma taxa/ cobrança ambiental para internalizar os custos da degradação e escassez pelo princípio do usuário-pagador.

Um exemplo da aplicação do referido princípio pode ser visto nas denominadas green taxes (taxas verdes), existentes em alguns países da Europa, onde são cobradas taxas pela utilização de bens causadores de degradação ambiental. Dessa forma, com o advento dos veículos movidos a gás natural ou 
equipados como motores híbridos - os quais emitem uma quantidade significativamente mais baixa de $\mathrm{CO} 2$ - a cobrança dessas taxas inexiste ou é consideravelmente mais baixa. Aliado a isso, em muitos casos, os impostos sobre a propriedade desses veículos também são reduzidos em relação aos veículos equipados com o clássico motor à combustão, de ciclo Otto.

\section{PRINCÍPIO DA COOPERAÇÃO INTERNACIONAL}

A sociedade de risco (BECK, 1992) trouxe consigo a problemática da necessidade de gestão dos novos riscos provenientes dessa sociedade, que se caracterizam pela sua globalidade (isto é, os riscos são transfronteiriços, de modo que os efeitos de um dano ambiental não se limitam ao território do Estado no qual foi causado o dano, mas se estendem inexorávelmente aos Estados vizinhos, podendo alcançar, por vezes, territórios de Estados muito distantes), invisíveis e transtemporais. Em razão da globalidade do risco, há a necessidade de se fortalecer as relações entre os Estados nacionais no sentido de evitar a ocorrência dos danos ambientais de escala global. Isso porque, conforme já salientado, fenômenos poluidores costumeiramente ultrapassam a fronteira de uma nação e atingem o território de outra, o que se pode vislumbrar nos "casos de emissão de poluentes na atmosfera, vindo a causar o efeito estufa, de consequências transfronteiriças", ou como no caso da "poluição marinha, que é levada de um país a outro pelas correntes marinhas" (MARCHESAN; STEIGLEDER; CAPPELLI, 2008, p.40).

O paradigmático caso de Chernobyl é, sem dúvida, o mais rico em demonstrar as características dos riscos oriundos da sociedade de risco. Com efeito, cerca de 21 anos após o acidente que provocou a explosão do reator $n^{\circ}$ 4 da Usina de Chernobyl, a radiotividade espalhada mantém-se em níveis elevados em várias partes da Europa. Isso porque o vento espalhou a radiação por países como a Suécia, Letônia, Polônia, Alemanha, Inglaterra e França (risco global). Em determinadas regiões da antiga União Soviética recomenda-se que frutas silvestres, cogumelos e peixes não sejam consumidos pelos próximos 40 anos (risco transtemporal). Em Belarus, 10 anos após o acidente nuclear ainda nasciam bebês sem braço, olhos ou com membros atrofiados (CHERNOBIL, 2011). Diante de casos como o de Chernobyl, vislumbra-se a necessidade de cooperação entre os Estados no que se refere a tutela do meio ambiente, a fim de evitar que casos assim se repitam.

Dessa forma, permeia o princípio da cooperação intergeracional o princípio da solidariedade, segundo o qual países desenvolvidos devem ajudar na 
transferência de tecnologia e conhecimento científico que permitam o desenvolvimento sustentável e a proteção do meio ambiente nos países subdesenvolvidos.

Os tribunais brasileiros já reconheceram a normatividade das Convenções internacionais ratificadas pelo Brasil. Como exemplo, com fundamento na Convenção Relativa à Proteção do Patrimônio Mundial, Cultural e Natural, o Superior Tribunal de Justiça declarou a ilegalidade da colocação de grades nos pilotis de prédio residencial, localizado na Região Administrativa do Cruzeiro/ DF, área tombada como Patrimônio Histórico e Artístico Nacional, razão pela qual deve ser livre o acesso a tal área, sobretudo por ter sido esse o desiderato quando da concepção arquitetônica de Brasília, uma cidade aberta, com trânsito livre e desimpedido de pessoas nos seus espaços arquitetônicos e paisagísticos (BRASIL, 2010).

\section{PRINCÍPIO DA PARTICIPAÇÃO COMUNITÁRIA}

Tendo em vista o dever do poder público e da coletividade de preservar o meio ambiente, a participação popular deve ser fomentada a fim de que os cidadãos participem da tutela ambiental.

A Audiência Pública realizada no âmbito do procedimento do licenciamento ambiental é um claro exemplo da participação popular na tutela do meio ambiente. Salientam Marchesan, Steigleder e Cappelli (2008, p.64) que o grande mérito do procedimento de licenciamento ambiental é "possibilitar o controle da discricionariedade administrativa e da motivação do órgão ambiental em relação ao processo decisório" que resultará na concessão ou não da licença para exercício da atividade que utiliza recurso ambiental considerada efetiva ou potencialmente poluidora.

Com efeito, sempre que o órgão ambiental licenciador julgar necessário, ou quando for solicitado por entidade civil, pelo Ministério Público ou por 50 (cinqüenta) ou mais cidadãos, promoverá a realização de Audiência Pública, conforme previsão do art. $2^{\circ}$ da Resolução $n^{0}$ 09/87 do CONAMA. Com efeito, no caso de haver solicitação de audiência pública e o órgão licenciador não realizá-la, a licença não terá validade $\left(\operatorname{art.} 2^{\circ}, \S 2^{\circ}\right.$, da Resolução 09/87 do CONAMA). Dessa forma, juntamente com o RIMA, os debates e as proposições dos presentes na Audiência Pública servirão de base para o parecer final do órgão licenciador quanto à aprovação ou não do projeto. 
A Ação Civil Pública também se revela em um instrumento coletivo de tutela do meio ambiente, por meio do qual o Ministério Público (art. 129, inciso III, da Constituição Federal) reprime ou impede danos ao meio ambiente, ao consumidor, a bens e direitos de valor artístico, estético, histórico, turístico e paisagístico e a qualquer outro interesse difuso ou coletivo (art. $1^{\circ}$ da Lei $n^{\circ}$ 7.347/85). Conforme ressalta Ferreira (2010), a ação civil pública é, atualmente, o mais importante meio processual de defesa ambiental, tendo sido também agasalhado pelo texto constitucional, por meio do art. 129, III, da CF/88. A jurisprudência do Superior Tribunal de Justiça é firme no sentido de que é possível cumular pedido de condenação em dinheiro e obrigação de fazer em sede de ação civil pública (BRASIL, 2011).

Por fim, o art. $5^{\circ}$, inciso LXXIII, da Constituição Federal legitima qualquer cidadão a propor ação popular que vise a anular ato lesivo ao meio ambiente e ao patrimônio histórico e cultural, ficando o autor, salvo comprovada má-fé, isento de custas judiciais e do ônus da sucumbência.

\section{PRINCÍPIO DA FUNÇÃO SOCIAL DA PROPRIEDADE}

O direito de propriedade deixou há muito de ser um direito absoluto. $\mathrm{O}$ exercício dele não se coaduna mais com a livre vontade do proprietário. Com efeito, a fruição da propriedade passou a enfrentar limite na denominada função social desta, de tal forma que não se pode mais falar em direito de propriedade dissociado de função social. Nesse sentido, lecionam Marchesan, Steigleder e Cappelli (2008, p.28) que o direito de propriedade não mais é concebido como algo que se "exerce em proveito exclusivo de seu titular, mas deve reverter para o coletivo, seja ela rural ou urbana".

O termo função exprime não só a idéia de abstenção de condutas negativas, como não poluir, não perturbar a vizinhança, não desmatar o solo, como também condutas positivas, consistentes na utilização racional e adequada do solo, no respeito às normas ambientais, como a manutenção da reserva legal e das áreas de preservação permanente. Após a constitucionalização da função social da propriedade, ocorrida com o advento da Constituição Federal de 1988, a partir de disposto no art. $5^{\circ}$, inciso XXIII, o legislador civilista houve por bem minudenciar o conceito de função social e o fez por meio da redação do artigo $1.228, \S 1^{\circ}$, do Código Civil, que prevê que o "direito de propriedade deve ser exercido em consonância com suas finalidades econômicas e sociais e de modo que sejam preservados, de conformidade com o estabelecido em lei especial, a 
flora, a fauna, as belezas naturais, o equilíbrio ecológico e o patrimônio histórico e artístico, bem como evitada a poluição do ar e das águas". O Supremo Tribunal Federal já alinhou em sua jurisprudência - que veio a originar a Súmula 668 -, que o único caso em que é lícita a progressividade das alíquotas do IPTU, antes da Emenda Constitucional 29/2000 (que veio a autorizar a progressividade do tributo em razão do valor do imóvel e de acordo com a localização e o uso do imóvel), é no caso de a progressividade das alíquotas visar a assegurar o cumprimento da função social da propriedade.

O princípio da função social da propriedade justifica, nessa medida, a intervenção pública na propriedade privada tendente a fazer valer a proteção ambiental. Nesse sentido, o Supremo Tribunal Federal já acenou que ao mesmo tempo em que a Constituição Federal garante o direito de propriedade - não impedindo, assim, a livre fruição da propriedade - a condicionou aos termos da lei. Dessa forma, entende o STF que a propriedade pode ser livremente fruída desde que: [a] respeitado o aproveitamento racional dos recursos naturais e $[\mathrm{b}]$ respeitadas as condições necessárias à preservação ambiental dos espaços e de seus recursos (BRASIL, 1995) .

Assim, sempre que houver deficiência no cumprimento da função social por parte do particular, está autorizado o poder público a adotar medidas expropriatórias que, por outro lado, também não podem ser resultado de ações públicas excessivas e arbitrárias. Ademais - e aqui o próprio STF concorda com essa posição - a retirada do poder sobre a propriedade com base na função social da propriedade (como a criação de áreas protegidas dentro da propriedade), não prescinde do dever de indenizar pelo Poder Público. Esse entendimento é consentâneo com a idéia de que cabe não só ao particular, mas ao Poder Público e à coletividade, a proteção ao meio ambiente, de forma que não pode o particular arcar isoladamente com o "ônus" da proteção ambiental (BRASIL, 1995).

\section{CONCLUSÃO}

Para a consolidação do Estado Socioambiental de Direito ficou assentada a importância dos princípios na tutela do bem ambiental, sobretudo diante da dinâmica dos riscos ambientais que sobreveio com a sociedade de risco. Com efeito, a clausura operacional vigente no âmbito das regras jurídicas não se mostra adequada à efetiva tutela do meio ambiente, sendo mais consentânea com a dinâmica da sociedade de risco a aplicação dos princípios ambientais 
enquanto reguladores das atividades potencialmente danosas ao meio ambiente. No Brasil, há um elenco considerável de doutrinadores e juristas que - contrapondo-se as teses do positivismo exegético-normativista -, defendem a força dos princípios ambientais constitucionais, questão que assume maior visibilidade pelo art. 225 da CF, que reflete e se compromete com um Estado Socioambiental de Direito para as presentes e futuras gerações.

Constatou-se isso por meio do princípio da responsabilização do poluidor-pagador, o qual, mesmo tendo sido um dos primeiros a exsurgir na ordem jurídica ambiental e diante de diversas regras posteriores que vieram a minudenciá-lo, não perdeu aplicação, sendo constantemente invocado pelos Tribunais pátrios a fim de determinar a recuperação ou compensação do dano ambiental.

Ademais, a importância da jurisprudência na construção do Direito Ambiental e a afirmação de seus valores e princípios é crescente, sobretudo diante da necessidade da interpretação interdisciplinar que reclama o Direito Ambiental, o que encontra seu locus de aplicação nas decisões pretorianas.

\section{REFERÊNCIAS}

ÁlVAREZ, Luis. Ortega. Lecciones de derecho del medio ambiente. 2. ed. Valladolid: Lex Nova, 2000.

ARAGÃO, Alexandra. Direito Constitucional do Ambiente da União Européia. In: CANOTILHO, José Joaquim Gomes; LEITE, José Rubens Morato (org.). Direito Constitucional Ambiental Brasileiro. 3.ed. São Paulo: Saraiva, 2010.

AYALA, Patryck de Araújo. A Proteção Jurídica das Futuras Gerações na Sociedade do Risco Global: O Direito ao Futuro na Ordem Constitucional Brasileira. In: Ferreira, Helini Sivini; Leite, José Rubens Morato; Boratti, Larissa Verri (org.). Estado de Direito Ambiental: Tendências. 2.ed. Rio de Janeiro: Forense Universitária, 2010.

AYLA, Patrick de Araújo. Mínimo existencial ecológico e proibição de retrocesso em matéria ambiental: considerações sobre a inconstitucionalidade do Código do Meio Ambiente de Santa Catarina. In: LECEY, Eladio; 
CAPPELLI, Silvia. Revista de Direito Ambiental. Ano 15, n. 60, out./dez./2010, p. 329-371. São Paulo: Revista dos Tribunais, 2010.

BECK, Ulrich. Risk society: towards a new modernity. Londres: Sage, 1992.

. Risk society and the provident State. In: Lash, Scott; Szerszynski, Bronislaw; Wynne, Brian (coord.). Risk, environment and modernity: towards a new ecology. Londres: Sage, 1998.

BENJAMIN, Antônio Herman de Vasconcellos e. Objetivos do Direito Ambiental. In: Anais do $5^{\circ}$ Congresso Internacional de Direito Ambiental: o futuro do controle da poluição e da implementação ambiental. Realizado de 4 a 7 de junho de 2001 em São Paulo. São Paulo: IMESP, 2001.

BORGES, Fernanda Gabriela. Responsabilidade Corporativa: a dimensão ética, social e ambiental na gestão das organizações. VILELA JUNIOR, Alcir; DEMAJOROVIC, Jacques (orgs.). Modelos e ferramentas de gestão ambiental: desafios e perspectivas para as organizações. São Paulo: Senac, 2006.

BRASIL. REsp n ${ }^{\circ}$ 840.918/DF, Relatora Ministra Eliana Calmon e Relator para Acórdão Ministro Herman Benjamin, Segunda Turma do Superior Tribunal de Justiça, DJe de 10/09/2010.

. Superior Tribunal de Justiça. REsp n⿳0 1.115.555/MG, Relator Ministro Arnaldo Esteves Lima, Primeira Turma do Superior Tribunal de Justiça, DJe de 23/11/2011.

. Superior Tribunal de Justiça. REsp n⿳亠口冋 1.094.873/SP, Relator Ministro Humberto Martins, Segunda Turma do Superior Tribunal de Justiça, DJe de 04/08/2009. Disponível em: http://www.stj.jus.br/webstj/processo/ justica/detalhe.asp?numreg=200802154943. Acesso em: 15.03.2012.

Superior Tribunal de Justiça. REsp 302906/SP, rel. Min. Herman Benjamin, Julgado em 26.08.2010. Disponível em: www.stj.gov.br. Acesso em: 15.03.2012. 
. Supremo Tribunal Federal. Recurso Extraordinário no 134.2978/SP. Relator Ministro Celso Antônio de Mello. DJu de 22/09/1995. Disponível em: <www.stf.gov.br/docID=207731> . Acesso em: 20 de Jan. de 2012.

BROWN WEISS, Edith. International equity: a legal framework for global environmental change. In: BROW WEISS, Edith (ed.). Environmental Change and International Law: new Challenges and Dimensions. Tóquio, United Nations University Press, Editado em Hong Kong por Permanent Typesetting and Printing CO., Ltd,, 1992.

CARVALHO, Délton Winter de. Dano ambiental futuro: a responsabilização civil pelo risco ambiental. Rio de Janeiro: Forense Universitária, 2008.

CANOTILHO, José Joaquim Gomes. Direito Constitucional e Teoria da Constituição. 3. ed. Coimbra: Almedina, 1998.

Introdução ao direito do ambiente. Lisboa: Universidade Aberta, 1998.

. Direito Constitucional Ambiental Português: tentativa de compreensão de 30 anos das gerações ambientais no direito constitucional português. In: CANOTILHO, José Joaquim Gomes; LEITE, José Rubens Morato (org.). Direito Constitucional Ambiental Brasileiro. 3. ed. São Paulo: Saraiva, 2010.

CHERNOBYL Radiation Disaster Information - Chernobyl Information. Disponível em: $<$ http://www.chernobyl.com/info.htm $>$. Acesso em: 13/12/2011.

DE GIORGI, Raffaele. Direito, democracia e risco: Vínculos com o futuro. Porto Alegre: Sérgio Antonio Fabris Editor, 1998.

FAZOLLI, Silvio Alexandre. Bem jurídico ambiental: por uma tutela coletiva diferenciada. Porto Alegre: Verbo Jurídico, 2009. 
FERREIRA, Helini Sivini. O Risco Ecológico e o Princípio da Precaução. In: FERREIRA, Helini Sivini; LEITE, José Rubens Morato (org.). Estado de Direito Ambiental: Tendências. Rio de Janeiro: Forense Universitária, 2004.

. Os Instrumentos Jurisdicionais Ambientais na Constituição Brasileira. In: CANOTILHO, José Joaquim Gomes; LEITE, José Rubens Morato (org.). Direito constitucional ambiental brasileiro. 3. ed. rev. São Paulo: Saraiva, 2010.

FIORILLO, Celso Antônio Pacheco. Curso de direito ambiental brasileiro. 11. ed. rev., atual. e ampl. São Paulo: Saraiva, 2010.

GIRAUD, Catherine. Le droit et le príncipe de précaution: leçons d'Australie. Revue Juridique de I'environnement, R.J.E. 1997, n. 01, p. 21-36.

LEITE, José Rubens Morato; BELLO FILHO, Ney de Barros. Direito ambiental contemporâneo. Barueri: Manole, 2004.

LEITE, José Rubens Morato; AYALA, Patryck de Araújo. Direito ambiental na sociedade de risco. Rio de Janeiro: Forense Universitária, 2002.

MACHADO, Paulo Affonso Leme. Estudos de Direito Ambiental. São Paulo: Malheiros, 1994

, O Princípio da precaução e o Direito Ambiental. Revista de Direitos Difusos. Organismos geneticamente modificados, São Paulo, v. 8, p. 1081-1094, ago., 2001.

MARCHESAN, Ana Maria Moreira; STEIGLEDER, Annelise Monteiro; CAPPELLI, Sílvia. Direito Ambiental. Porto Alegre: Verbo Jurídico, 2008,

MOLINARO, Carlos Alberto. Direito ambiental: proibição de retrocesso. Porto Alegre: Livraria do Advogado, 2007.

MOTA, Ronaldo Seroa da. Economia Ambiental. Rio de Janeiro: FGV, 2006. 
NOGUEIRA, Ana Carolina Casagrande. O Conteúdo Jurídico do Princípio da Precaução no Direito Ambiental Brasileiro. In: FERREIRA, Helini Sivini; LEITE, José Rubens Morato (org.). Estado de Direito Ambiental:

Tendências. Rio de Janeiro: Forense Universitária, 2004.

OST, François. O tempo do direito. Tradução de Élcio Fernandes. Bauru: EDUSC, 2005

PRIGOGINE, Ilya. O fim das certezas: tempo, caos e as leis da natureza. São Paulo: Unesp, 1996.

RIBAS, Lídia Maria L.R.; CARVALHO, Valbério Nobre de. O tributo como instrumento de tutela do meio ambiente. In: LECEY, Eladio; CAPPELLI, Sílvia (coord.). Revista de Direito Ambiental, ano 14, $\mathrm{n}^{\mathrm{0}}$ 54, abr./jun./ 2009. São Paulo: Revista dos Tribunais, 2009.

\section{SARCINELLI, O. Análise Econômica da adoção de medidas}

mitigadoras de impactos agro-ambientais: estudo de caso na microbacia hidrográfica do córrego Oriçanguinha. 2008. Dissertação (Mestrado em Desenvolvimento Econômico) - Instituto de Economia da Universidade Estadual de Campinas (UNICAMP), Campinas: 2008. Disponível em: $<$ http://www.eco.unicamp.br/docdownload/monografias/Oscar_Sarnelli.pdf $>$. Acesso em: 23 jan. 2012.

Recebido em: 12/04/2012 Aprovado para publicação em: 15/04/2013

Como citar: HUPFFER, Haide Maria; WACLAWOVSKY, William Gabriel; GREENFIELD, Roberta Cassel. Os Princípios do Estado Socioambiental de Direito e sua Leitura Jurisprudencial. Revista do Direito Público, Londrina, v.8, n.1, p.155-176, mai.2013. DOI: 10.5433/1980-511X.2013v8n1p155. 